\section{Tempos de elegância: memória e história nas páginas da revista Rio}

Ana Luiza CERBINO ${ }^{1}$

Resumo: Este artigo tem como objeto de análise a revista Rio, editada entre as décadas de 1940 e 1950, na cidade do Rio de Janeiro. Parte-se do pressuposto de que o periódico é um "lugar de memória", pois realizava uma operação seletiva do que deveria ser lembrado e esquecido. Em páginas encontram-se traços e vestígios de uma parte da sociedade que se fez reconhecer, impondo uma visão da realidade perpassada pelo glamour e pela elegância. Busca-se dimensionar seu significado em um cenário mais amplo do impresso no Brasil, principalmente no que diz respeito ao entendimento do universo e do imaginário do período. Um periódico, contudo, que por se inserir no chamado conjunto de publicações frívolas, não tem sido alvo de nenhum tipo de reflexão.

Palavras-chave: Revista Rio; memória; história.

\section{Los tiempos de la elegancia: la memoria y la historia en las páginas de la revista Rio}

Resumen: Este artículo tiene como objeto de análisis la revista Rio, publicado entre los años 1940 y 1950, en la ciudad de Rio de Janeiro. Parte del supuesto de que la revista es un "lugar de memoria", por lo tanto realizava una operación selectiva de lo que debe ser recordado y olvidado. In sus paginas, hay rastros y restos de un sector de la sociedad que se hizo conocida, a imponer una visión de la realidad impregnada por el glamour y la elegancia. Pretende medir su significado en un escenario más amplio de lo impresso en Brasil, sobre todo en lo que respecta a la comprensión del universo y el período de

1 Doutora pelo Programa de Pós-graduação em Comunicação/PPGCOM, pela Universidade Federal Fluminense/UFF. Possui textos publicados em revistas acadêmicas e anais de congressos, com pesquisa sobre periódicos ilustrados na interseção da comunicação e do design. É professora do Curso de Comunicação/Publicidade e Propaganda da Universidade Estácio de Sá/RJ. E-mail: alcerbino@gmail.com. imaginaria. Un diario, sin embargo, que mediante la inserción del número de llamada de publicaciones frívolas no se ha sometido a ninguna reflexión.

Palabras clave: Revista Rio; memoria; historia.

\section{Revistas como "lugar de memória"}

Como a materialidade de um determinado periódico pode ser interpretada e entendida? Ao se tratar de um impresso o questionamento do passado ajuda a construir o presente, considerando «O passado como objeto de uma interpretação». São traços e vestígios que deixam marcas impressas em um suporte, elaborando a percepção de determinado momento. Imagens, cores e texturas constituem formas visuais que correspondem a linguagens específicas e datam visualmente um espaço social. Idéias gráficas que se cruzam e constituem não só um repertório visual como também cultural.

Busca-se entender o objeto revista inscrito em um fazer social, em que as ideias ali impressas inserem-se em um processo mais amplo. Perceber, enfim, as práticas sociais que ali se articulam e dão visibilidade a determinados grupos e como suas especificidades materiais contribuem para isso.

As revistas, portanto, são também portadoras de uma memória. Carregam discursos e narrativas que podem ser entendidos como documentos. Parte-se da premissa de que esses objetos são "lugares de memória", segundo acepção de Pierre Nora (1993), na medida em que é seu papel selecionar temas que devem ser lembrados e esquecidos. Ao elencar o que deve ser notícia e o que será esquecido, ao valorizar determinados aspectos em detrimentos de outros, o presente é reconstruído de forma seletiva, estabelecendo uma espécie de índice para o leitor. E entender a revista como tal significa também "deter o tempo e bloquear o trabalho do esquecimento", para assim percebê-la como um "lugar privilegiado", pois ali estão presentes estratégias de legitimação de uma determinada parte da sociedade. Nesse sentido, a revista não é um espaço inocente muito menos transparente, ao contrário.

É fundamental o entendimento do conceito de lugar de memória, que abrange,

Museus, arquivos, cemitérios e coleções, festas, aniversários, tratados, processos verbais, monumentos, santuários, associações (...). Os lugares de memória nascem e vivem do sentimento que não há 
memória espontânea, que é preciso criar arquivos, que é preciso manter aniversários, organizar celebrações, pronunciar elogios fúnebres, notariar atas, porque essas operações não são naturais. (Nora, 1993, p. 13)

Os lugares de memórias não dependem da natureza concreta que os define, mas daquilo que os habita. Tal ocorre porque a memória necessita ser alimentada no cotidiano e a partir dele, já que ela não é natural, mas uma construção realizada no presente e em constante movimento, pois ela não é a lembrança, mas o esquecimento. Por isso precisa de ritos, de ordenações, de um lugar para estar e sobreviver. Vale ainda ressaltar que os lugares de memória revelam processos sociais, interesses e embates, que por sua vez representam as "marcas do tempo".

Neste sentido, a periodização das revistas acaba por organizar a memória, pois o que Nora chama de memória, é de fato, no seu entender, "uma constituição gigantesca e vertiginosa do estoque material daquilo que nos é impossível lembrar, é repertório insondável daquilo que poderíamos ter necessidade de lembrar". (1993, p. 15)

O conceito é aqui compreendido em um triplo sentido: lugares materiais, em que a memória social se ancora e pode ser apreendida pelos sentidos; lugares funcionais, porque têm ou adquiriram a função de alicerçar memórias coletivas, e lugares simbólicos, onde essa memória coletiva se expressa e se revela. (Nora, 1993, p. 21) Ao entender a revista a partir de sua materialidade, funcionalidade e simbolismo é possível encontrar impressa nas páginas de Rio a memória específica de um grupo social, revelando a construção de uma identidade pautada no luxo e no glamour. Um grupo que se fez representar na revista por uma narrativa visual requintada e moderna. Contudo, não podemos esquecer que a memória não é apenas uma conquista de indivíduos ou coletividades, mas é também um instrumento e um objeto de poder.

Ao registrar em suas páginas fatos e notícias, os acontecimentos do cotidiano e suas transformações, Rio ajudou a produzir sentido para os processos históricos em andamento naquele momento, destacando o que e quem deveria ser lembrado, mais ainda, como estes seriam rememorados.

A memória, portanto, deve ser entendida em constante estado de transformação, "vulnerável a todos os usos e manipulações" e, por essa razão, atuando sempre no presente e como fundadora de identidades.
(Nora, 1993) Assim, a memória carrega traços culturais e históricos não só de resistência, mas também de construção de representações culturais de uma sociedade, de um grupo ou de um indivíduo.

Percebe-se, portanto, que os lugares de memória não são um simples espaço para registro, representam mais que isso. São os resíduos e os testemunhos; são os depositários que condensam simultaneamente um espaço e um tempo. Tais lugares começam onde o mero registro termina, tornando-se o simbólico e/ou o emblemático inscrito no presente.

\section{O tempo e o espaço de Rio}

Lançada no mercado editorial no início dos anos 40 e editada até finais da década de 1950, Rio atravessou o período do Estado Novo (1937-1945), época em que mudanças políticas e sociais foram instauradas, transformando também os produtos impressos então publicados.

Nesse período, a ditadura criou, em 1939, um órgão específico, o Departamento de Imprensa e Propaganda, o DIP, chefiado por Lourival Fontes (1899-1967), que controlava a imprensa e o rádio, apontando o que poderia ou não ser notícia (Sodré, 1966, p. 439). O Estado adquiriu a exclusividade da divulgação nos principais periódicos do país, mas o público de forma geral foi afastado; sua fala foi silenciada dos jornais, enquanto a do Estado foi ampliada. (Barbosa, 2007a)

O Estado buscava a construção de um ideal de nação, fazendo prevalecer uma determinada ideia de direcionamento político e intelectual dos que estavam no poder. E nesse processo, a organização nacional passou pela formação de nação definida pelo projeto político vigente, instaurando, consequentemente, "a naturalização da ideia de hierarquia entre os grupos sociais". (idem, p.105)

É possível afirmar que o surgimento de uma publicação como Rio foi consequência direta desse momento e, ao mesmo tempo, uma exigência do público que buscava a atmosfera de luxo e fantasia em lugar da realidade política. $\mathrm{Na}$ revista, o glamour se sobrepôs ao cotidiano, tornando-se lugar estratégico da articulação sócio-cultural da cidade. Ao se encontrar afastado da realidade política, o leitor mostrou sua face nesse tipo de periódico que enfocava o entretenimento, buscando assim outras possibilidades para vivenciar seu cotidiano.

Rio também passou pelas mudanças ocorridas na imprensa carioca na década de 1950, quando o jornalismo empresarial foi pouco a pouco substituindo o político-literário da década anterior. No entender de Ribeiro 
(2003, p.1), "a imprensa abandonou a tradição de polêmica, de crítica e de doutrina, substituindo-a por um jornalismo que privilegiava a informação e que a separava do comentário pessoal e de opinião". E se até os anos 30 e 40 a imprensa dependeu dos favores do Estado, além de pequenos anúncios populares e da publicidade das lojas comerciais, nos anos 50, a imprensa passou a sobreviver cada vez mais com a venda avulsa ou por assinatura, com a publicidade comercial, com privilégios públicos e apoios de grupos privados. (Ribeiro, 2001, p. 42)

As transformações na estrutura produtiva do país, em especial das indústrias, possibilitaram a formação de uma sociedade de consumo. Ao mesmo tempo, houve uma padronização do consumo provocada pela expansão da propaganda na mídia impressa. Anúncios de produtos de beleza, utensílios e eletrodomésticos, carros, entre outros saltavam das páginas das revistas, criando novos hábitos e, simultaneamente, despertando desejos e necessidades. Os eletrodomésticos facilitavam os afazeres da casa, o carro possibilitava maior mobilidade na locomoção urbana e nas viagens de férias. As radiovitrolas disputavam com o rádio e mais tarde com a TV, a promoção do entretenimento doméstico.

Contudo, a padronização dos hábitos de consumo e dos comportamentos atingia apenas uma pequena parcela da sociedade devido ao baixo padrão de vida da população brasileira. E essa pequena parcela estava presente em Rio não só como consumidora, mas também e, principalmente, como principal participante dessa sociedade de consumo.

Outro importante aspecto deve ainda ser destacado: a construção de um Rio de Janeiro não mais como "cidade civilizada", mas como metrópole internacional, onde personalidades do entretenimento, da política e da cultura aportavam. Perpetuava-se a imagem de uma capital que ditava modas e comportamentos, sistemas de valores, estilo de vida e sensibilidades. Contudo, o modelo perfeito de cidade não estava mais na Europa, a partir da década de 1940, construía-se a idéia de uma cidade idealizada via Hollywood, o novo padrão estético e irradiante de charme e glamour.

\section{Conhecendo a revista Rio}

A fim de conhecer um pouco de Rio podemos lançar um olhar para o expediente apresentado em seus números. Estes informavam sobre seus agentes no Rio de Janeiro e em São Paulo, além dos correspondentes em Paris, Nova Iorque, Roma, Lisboa e Buenos Aires. O número avulso custava na década de 1940 Cr\$ 15,00 saltando na década seguinte para $\operatorname{Cr} \$ 30,00$, e com a assinatura mensal ocorreu o mesmo, de Cr\$170,00 em 1948 pulou para Cr\$ 420,00 em 1956, resultado do aumento do custo de impressão. No entanto, não há indicação de sua tiragem em nenhum dos números, só a informação de que Rio era mensal.

Mas a partir desse silêncio, surgem e sobram algumas perguntas: como surgiu a ideia de sua publicação? A construção de um discurso e imagem de um país eram orientados por quais protagonistas? Ou seja, quem estava por trás das suas páginas? Quais eram as relações de sociabilidade entre seus produtores (editores, ilustradores/ artistas plásticos, jornalistas, etc.)? Muitas são as indagações e poucas as respostas encontradas. Nesse sentido, uma investigação profunda deve ser realizada não só para conhecer, mas principalmente, entender a publicação e suas particularidades.

As primeiras folhas eram dedicadas aos anúncios de páginas inteiras, a cores ou não, inicialmente com ilustração e depois, a partir da década de 1950, já usando imagens fotográficas. Ofereciam viagens pela Pan Am, pela Air France, automóveis Buick, refrigeradores da General Eletric, batedeiras da marca Walita, perfumes da Coty, cosméticos da Dorothy Gray entre muitos outros; e no final da revista encontravam-se os pequenos anúncios de produtos de higiene, de remédios e de restaurantes em geral.

Barbosa (2002) aponta uma prática comum na época, usada em O Cruzeiro e presente também em Rio: as matérias não eram apresentadas na sua totalidade em sequência, isto é, havia sempre uma interrupção na continuidade com a parte final do texto vindo nas últimas páginas da revista. Para a autora, esse tipo de edição indica uma prática de leitura particular, em que o leitor lia de forma entrecortada, pois não havia uma noção de linearidade. Mas também, e principalmente, cabe destacar como essa prática aponta as opções de diagramação disponíveis e usadas naquele período, assim como a elaboração de um fluxo de imagens a partir dos temas ali tratados.

Em suas páginas encontram-se matérias sobre tardes na hípica, festas em boates e cassinos, bailes de debutantes, do Rio de Janeiro e de São Paulo, além dos casamentos do high society carioca e paulistano. Também estão presentes moda, entretenimento, crônicas e notas sociais, assim como as críticas de dança, teatro e música. Mais do que somente apresentar o cotidiano, a revista era um importante instrumento de um grupo social empenhado em "naturalizar" seus hábitos e costumes, em mostrar uma determinada forma de ver e reproduzir o

53 
mundo. Os criadores dessa versão da realidade eram os freqüentadores do Night and Day, das soirrées no Casablanca, do Jocquey Club e dos verões em Petrópolis; eram os que assistiam aos espetáculos no Theatro Municipal em noite de black tie e que "vestiam os modelos da estação".

No número 64, de outubro de 1944, o editorial assinado pelo então diretor Sady Alves da Costa, chamado "Roberto Marinho na direção de 'Rio' ", apresentou o jornalista carioca como seu novo proprietário. Anunciava ainda as principais novidades na revista a partir da edição de novembro: a chegada do novo redator-chefe, Henrique Pongetti (1898-1979), além da ampliação do quadro de colaboradores que passaria a contar com nomes de "grande prestígio da literatura, da ilustração e da fotografia", como Athos Bulcão (1918-2008), Carlos Drummond de Andrade (1902-1987), Di Cavalcanti (1897-1976), Djanira (1914-1979), Elsie Lessa (19142000), Jaques Corseuil (1913-2000), Rachel de Queiroz (1910-2003), entre muitos outros.

Segundo o editorial, o novo time de colaboradores promoveria uma melhoria do periódico, ao aliar qualidade de conteúdo ao prestígio dos nomes. A publicação, de certa forma, reposicionava-se no cenário editorial a partir dessas inovações, mas sem perder o "carinho de seus leitores". No número seguinte, de novembro de 1944, um anúncio oferecia sua assinatura apontando-a como "a revista das elites". Rio desejava fazer parte não apenas de uma elite editorial, mas também de uma elite social.

A diagramação da revista tinha como referência o trabalho realizado pelo designer Alexei Brodovitch (1898-1971) para a revista feminina norte-americana Harper's Bazaar. A principal característica de sua linguagem visual era "a simpatia pelo espaço em branco e tipos precisos em páginas claras, abertas, repensando a abordagem do design editorial" (Meggs, 2009, p. 440). Mais do que definir um conceito estético, Brodovitch transformou a concepção de espaço e, consequentemente, de leitura, ao usar elementos em que o equilíbrio ajudava a "ler" imagem e texto. As páginas resultantes tinham como premissa a simplicidade, a novidade e a clareza, que a princípio pareciam se opor, mas que juntos construíam um estilo fluido e, ao mesmo tempo, elegante de apresentar a moda.

Elementos que também surgem nas páginas de Rio, presentes nas soluções gráficas elaboradas para as capas e páginas da revista que exibiam um refinamento visual no uso da imagem, da tipografia e do espaço em branco, estabelecendo uma simplicidade e limpeza visual até então inéditas no mercado editorial. Como na página dedicada as bailarinas Volkova e Leskova, em que a imagem fotográfica tem destaque nessa matéria de Jaques Corseuil e os espaços em branco ajudam a dar legibilidade às páginas como um todo. A fotografia de bordas sangradas da bailarina sentada, e que ocupa quase toda a página direita, cria um contraponto interessante com as imagens menores, que formam um "L". (Figura 1)

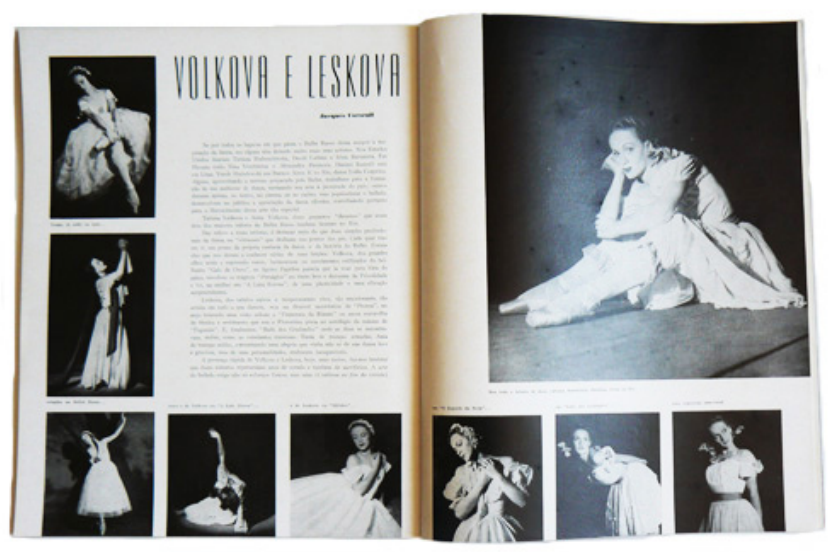

Figura 1: Outubro de 1944, edição 64, p. 98-99.

A revista traduzia simbolicamente sua qualidade por meio de sua excelência gráfica. Para isso utilizava o papel couché tanto para o miolo quanto para a capa, representando o requinte daquele universo. Já seu formato, 27,0 X 32,5 cm, era sinônimo de um produto mais luxuoso, destacando-se das outras publicações. A policromia era usada para a capa e contracapa, com o miolo impresso em p\&b, enquanto os anúncios podiam ter uma, duas ou até mesmo quatro cores. A impressão em offset garantia a fidelidade das imagens e uma suavidade nos matizes das tintas.

Nas capas de Rio, o texto era usado somente no nome da revista, sem chamadas específicas para as matérias internas, em que cada capa sugere e dá a ideia da principal reportagem do número, como a capa da edição de novembro de 1944. O número em questão apresenta duas matérias dedicadas ao tema da guerra: "Os museus e a guerra", sobre a situação dos museus da Europa durante o conflito, e "Para as crianças da França", sobre festa beneficente para angariar fundos para uma remessa de sapatos nacionais às crianças francesas, além de um poema de Cecília Meireles, "Declaração de amor em tempo de guerra”. Na ilustração desenvolvida pelo artista plástico Enrico Bianco três paraquedas coloridos (amarelo, vermelho e branco) criam o dinamismo da imagem que remete ao momento em questão - a guerra. O nome da revista aparece no canto esquerdo bastante condensado, todo em caixa alta, isto é, em letras maiúsculas, mas sem 
comprometer a percepção dos elementos do desenho. (Figura 2)

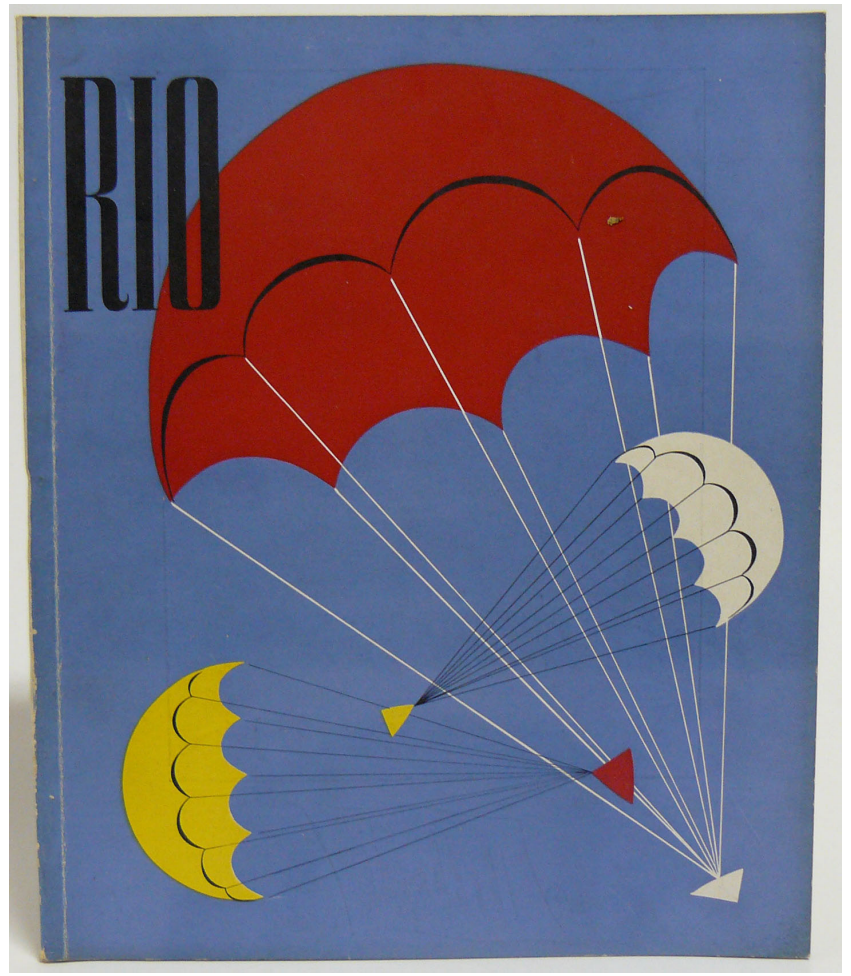

Figura 2: Capa de Enrico Bianco, n. 65, novembro de 1944.

Uma importante questão a ser ressaltada é que a guerra trouxe para o Rio de Janeiro intelectuais, nobres europeus falidos, celebridades, artistas, estrelas do cinema e da dança que incluíram a cidade na rota do jet-set internacional. Ao mesmo tempo que aqui desembarcavam também apareciam nas páginas de Rio, tanto nas matérias sobre os eventos sociais para os quais eram convidados, como jantares, vernissages, desfiles de moda, chás da tarde no Copa, quanto nos espetáculos em que se apresentavam nos teatros e nos cassinos.

Na edição de julho de 1945, no informe publicitário, "Variety no Copacabana", do Golden Room, no Copacabana Palace, apresenta assim suas atrações:

Traduzamos o título do maravilhoso espetáculo do "golden room" e teremos em brasileiro a chave do seu profundo agrado. Variedade, sim, mas variedade que vive da fulguração de um punhado de astros de fama mundial, como Evelyn Knight, Tâmara Grigorieva, Vaslav Weltcke, Tatiana Leskova, Anna Volkova, Alberto Sicardi, Wences e seus bonecos, além de uma plêiade de artistas de real valor. Estamos já nas grandes noites do "golden room", às vésperas do "Grande Prêmio Brasil" quando a elite de São Paulo vem ao Rio torcer pelos seus favoritos. Essas noites marcam no Copacabana o "clímax" da estação de inverno.

É possível perceber, de acordo com o texto, que os destaques eram as atrações internacionais, tanto para seduzir o seu público quanto para legitimar o Golden Room como um espaço internacional e elegante.

A matéria sobre a bailarina Nini Theilade (1915), da companhia do Ballet de Monte Carlo, que aqui chegou em 1940, também nos dá uma percepção da importância dessas personagens internacionais. Ao apresentar Theilade com sua filha, a matéria chama a atenção não só para a sua profissão, mas também para como a bailarina "poderia ser melhor aproveitada pelo bailado nacional". Além disso, apresenta Theilade como mãe carinhosa e dona de casa, já que sua profissão aqui no Brasil ainda era vista de forma reticente pelas famílias cariocas mais tradicionais. Buscava-se assim construir uma imagem diferente daquela do senso comum em relação às bailarinas e seu cotidiano. Chama atenção o uso das imagens: das seis fotos que compõem a matéria, apenas duas mostram a bailarina de malha e collant, com suas roupas de trabalho, as demais são fotos dela com sua filha ou sozinha. (Figura 3)

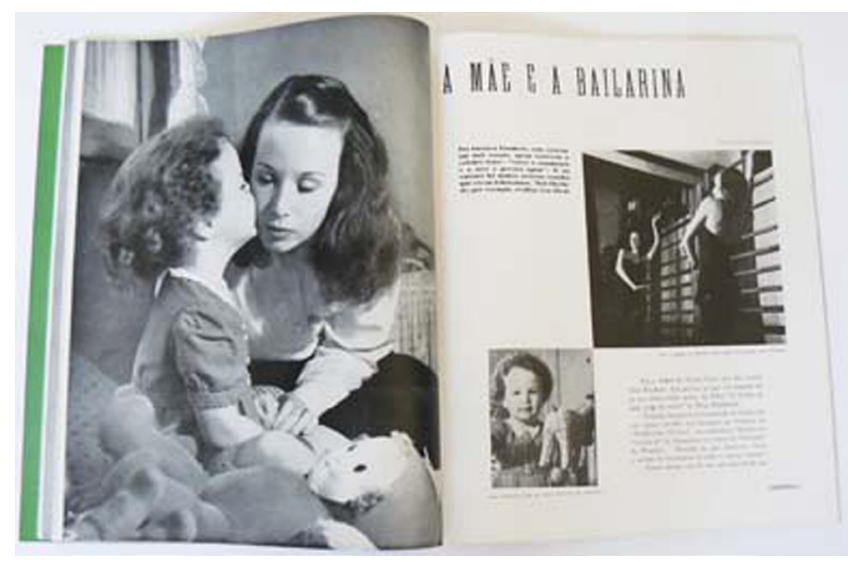




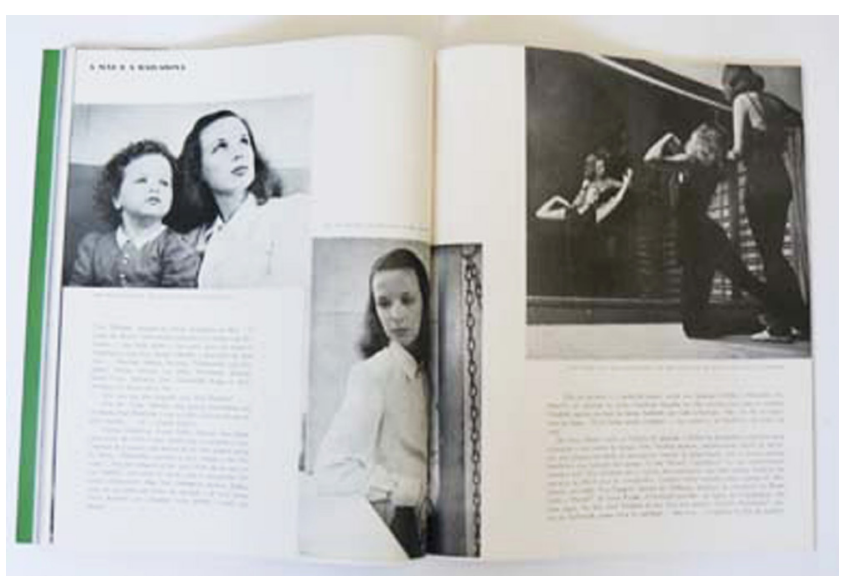

Figura 3: Matéria "A mãe e a bailarina”, com fotos de José Medeiros. Edição n. 83, maio de 1946, p.60-63.

Outra questão relevante diz respeito à renovação de alguns hábitos da sociedade carioca, como o colunismo social feito por Maneco Müller (1923-2005), que usava o pseudônimo de Jacinto de Thormes ${ }^{2}$. Nele, o colunista, a partir de década de 1940, deixou de lado o simples registro de nomes e sobrenomes da alta sociedade, como era comum, passando a escrever pequenos textos sobre os acontecimentos sociais que ocorriam na cidade. Redigia suas notas com "um estilo de crônica literária, algo até então inédito no país, com um misto de ironia, seriedade, esnobismo, fanfarronice e sarcasmo" (SOUZA, 2007). É possível dizer que sua coluna foi o embrião de uma cultura das celebridades, das colunas feitas de notas, do rompimento entre o público e o privado, que também podiam ser visualizados em Rio.

Na edição de outubro de 1956, um número dedicado aos acontecimentos sociais de São Paulo, a matéria "Maneco foi ao Juca's como quem vai à fonte", de Claudir Chaves e fotos de Armando Neves, mostra Maneco Müller já reconhecidamente um dos mais importantes colunistas sociais do país. Nela, o repórter faz perguntas diretas ao jornalista sobre Jacinto de Thormes e como ele percebia a sociedade naquele momento, traçando assim um rápido perfil do colunista. Sua opinião interessava e era relevante em função da sua atividade e como conhecedor dos meandros da sociedade carioca da época, já que atuava na televisão, no rádio e na mídia impressa (jornal e revista). O título da matéria já apontava o Juca's Bar como importante espaço de sociabilidade para a cidade, e como local para ver e ser visto.

2 Jacinto de Thormes é nome do personagem principal do romance "A cidade e as serras", de Eça de Queiróz, lançado em 1901. O livro relata como Thormes, representante da elite portuguesa, e adepto do progresso e da tecnologia, troca o mundo civilizado pelo mundo natural e com pouco conforto, mas onde encontra a felicidade, mudando assim de opinião sobre a vida no campo.
Outro aspecto a ser destacado é que em cada edição o nome da revista surgia com uma tipografia diferente, inserida na técnica usada e na cor também adequada. Tal ocorria muito em função da liberdade que os artistas/ilustradores tinham na concepção do desenho, pois não eram meras ilustrações desconectadas do conteúdo da edição, mas estavam em consonância com a principal matéria do número em questão. Eram concebidas para dar sentido a revista e nesse processo incorporavam o título, como nas capas desenvolvidas por Di Cavalcanti, Sansão Castelo Branco e Burle Marx. (Figura 4)

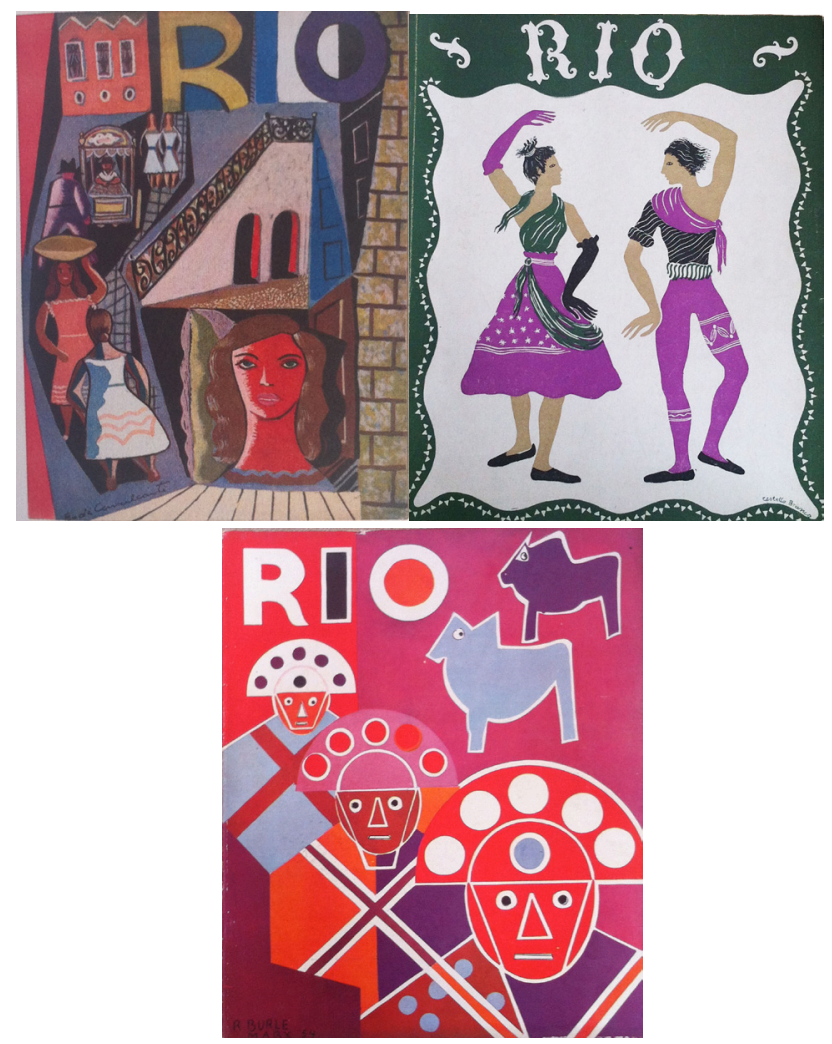

Figura 4: Capa de Di Cavalcanti, 1947; capa de Sansão Castelo Branco, 1946 e capa de Burle Marx, de 1954. Em cada uma delas o título da revista foi projetado para estar integrado à ilustração.

Uma década mais tarde, Michel Burton mesclou fotografia e ilustração em colagens modernas para as capas, fazendo uso do espaço em branco, o que confere uma "assinatura" às suas criações. No trabalho de Burton há uma matriz pictórica fundamentada na tipografia e no desenho e que seria, anos depois, aprofundada em outros projetos, como nos desenvolvidos para Senhor. Aqui são apresentadas duas capas de 1956: a de junho, n. 204, e a de setembro, n. 207, sendo a última realizada em conjunto com o fotógrafo Otto Stupakoff (1935-2009). (Figura 5) 

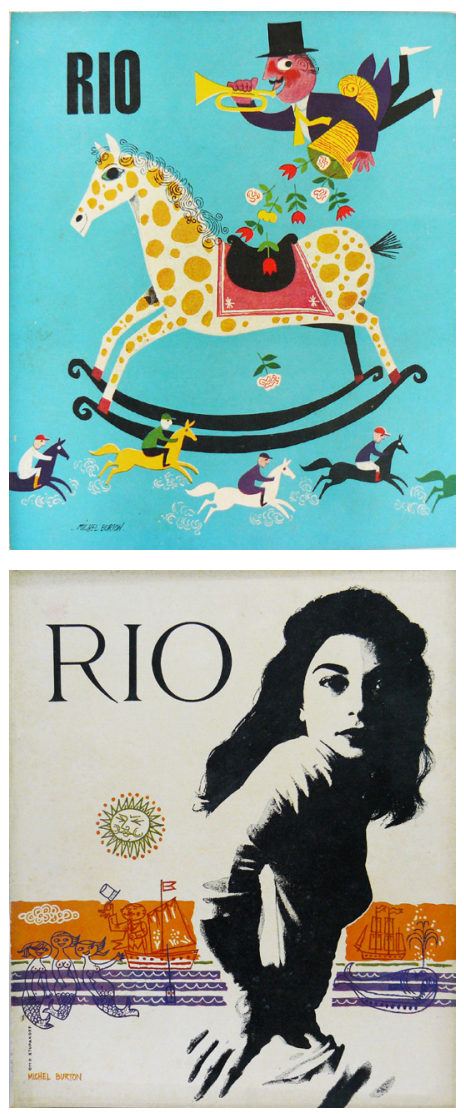

Figura 5: Capa da edição n. 204, de junho de 1956 e capa da edição n. 207, de setembro de 1956 .

Na edição de junho de 1956 começou a ser utilizado o slogan "a revista do mundo elegante", ao lado do expediente, reafirmando a sua linha editorial. Ao lado o índice com as matérias, colunas e crônicas dedicadas ao Grande Prêmio Brasil, no Jóquei do Rio de Janeiro. (Figura 6)

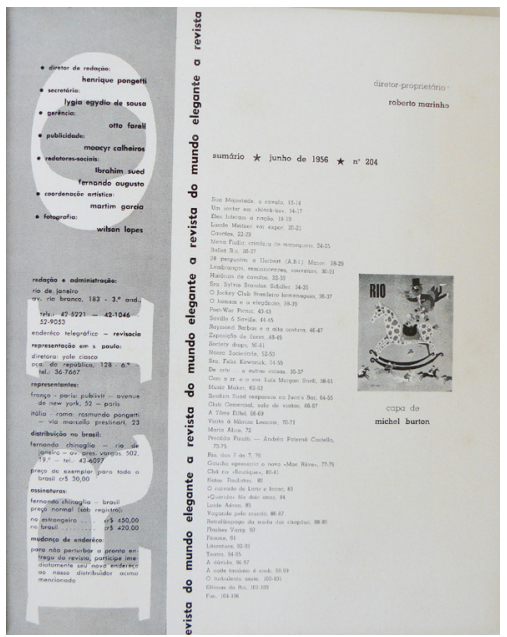

Figura 6: Expediente e índice da edição n. 204, junho de 1956.

O uso da ilustração nas páginas de propaganda ajudava a seduzir os leitores, já que as preocupações com a beleza e a juventude tornaram-se alvo da publicidade, justificando assim os inúmeros produtos de cosméticos e de higiene pessoal presentes na revista. Ao mesmo tempo, encontramos anúncios de roupas e acessórios femininos e masculinos, indicando que no contexto da vida moderna investir na aparência representava o acesso a locais privilegiados. Como nos anúncios de página inteira abaixo: o primeiro da marca Dorothy Gray, em duas cores, prometendo uma aparência sedutora e discreta, e o do perfume Lucien Lelong, em quatro cores. (Figura 7)
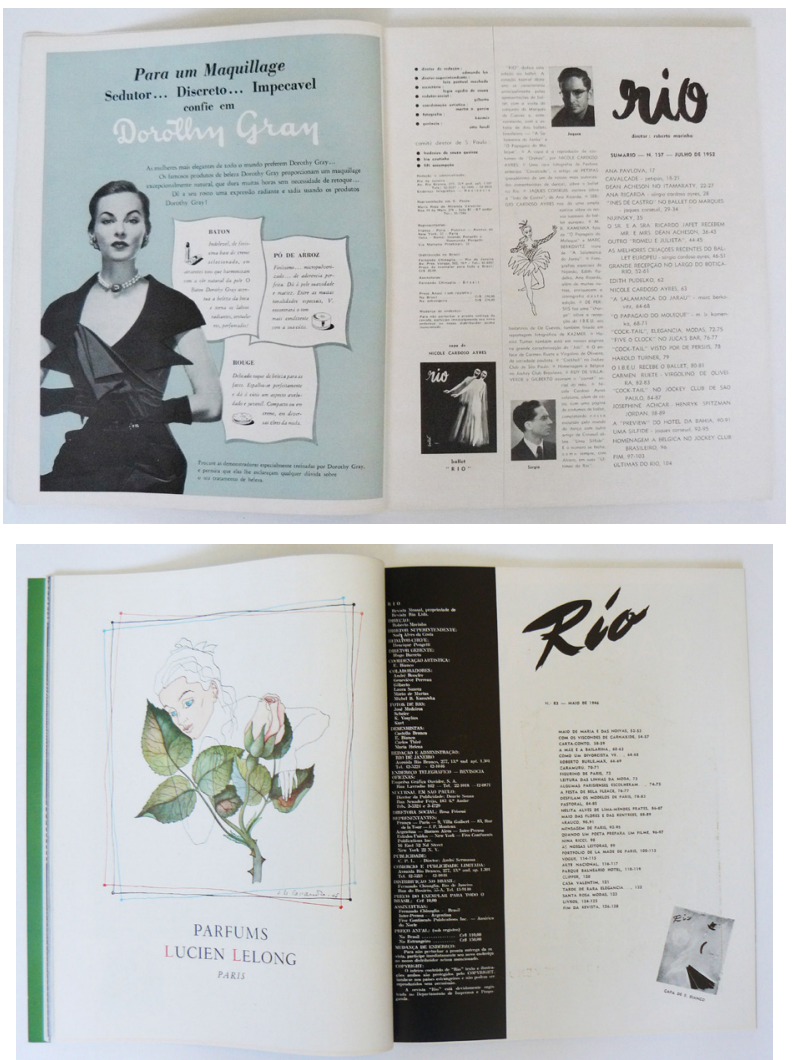

Figura 7: Edição n. 83, maio de 1946 e edição n. 157, julho de 1952.

Outros anunciantes significativos para a revista eram as marcas de cosméticos, como Elizabeth Arden e Helena Rubinstein, lançando não só perfumes mas também batons e pó facial. Também era comum que essas marcas veiculassem mais de um anúncio com diferentes produtos, como Elizabeth Arden, que também anunciava produtos especiais para a "cutis fina e delicada das jovens". Esses produtos - perfumes e cosméticos -, ganharam grande importância a partir da década de 1940, pois estar limpo e perfumado começava a ser importante tanto para homens quanto para mulheres que desejavam se enquadrar nos moldes de cuidados pessoais, beleza e aceitação. (BUENO, 2007)

Anúncios de casas de decoração ou de decoradores particulares eram comuns na revista, demonstrando 
que o leitor deveria se preocupar, além da sua elegância particular, com a sua moradia, como o da casa Régence.

Uma novidade para os leitores da revista era possibilidade de viagens para o exterior por avião, o que era um luxo para poucos, tanto para a América do Sul e do Norte quanto para a Europa. Mas nas páginas de Rio encontramos variados anúncios de companhias aéreas, como o das Linhas Aéreas Escadinavas (SAS), que prometia "mais conforto pelo mesmo preço" para várias capitais européias.

Já o relógio de pulso masculino era o complemento de elegância e distinção para o consumidor moderno, objeto importante tanto para o controle de sua rotina diária quanto para a construção de sua individualidade. Assim como o automóvel Buick, signo de luxo, com a potência de um "moderno avião". Essa comparação denota não só a preocupação com o que há de mais atual, como também com a força e a necessidade de estar em movimento, já que a cidade moderna era o espaço da ação, dos reflexos e do impulso.

Freqüentar a praia, em Copacabana ou no Arpoador, com a correta indumentária, em 1948, era a preocupação do anúncio do magazine A Exposição Carioca, anunciante assíduo da publicação. O "maillot" Catalina de duas peças era o que havia de mais moderno no momento, assim como o tecido usado, o látex, moldando a silhueta feminina. A praia, aos poucos, tornava-se um dos principais pontos de lazer da cidade e seus freqüentadores deveriam estar não só adequadamente vestidos, mas principalmente apresentar uma figura moderna proporcionada pelo produto em questão. (Figura 8)

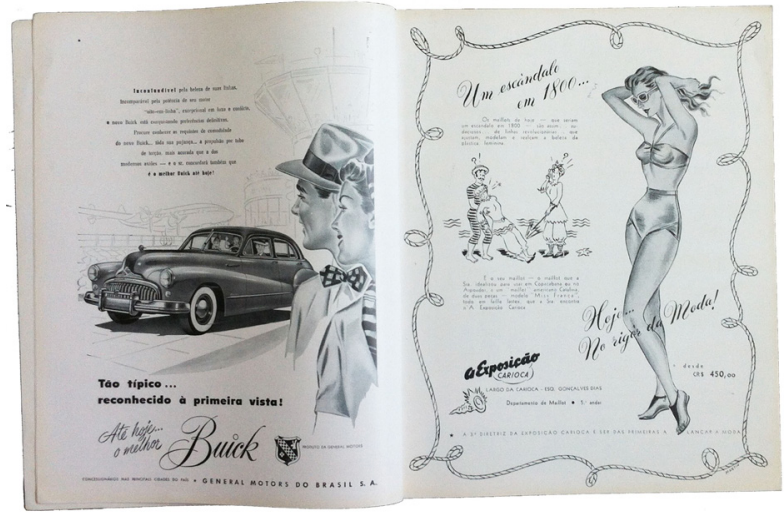

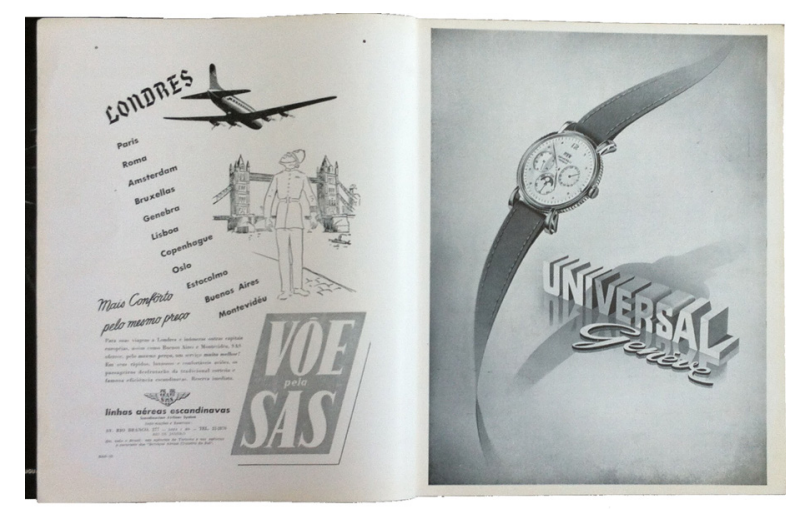

Figura 8: Rio, n. 112, p. 2-3, p. 4-5, p. 10-11.

A confluência entre artes plásticas e design presente nas capas e no miolo da revista possibilitou um diálogo profícuo entre ambos, já que naquele momento as capas e a diagramação eram realizadas, em sua grande maioria, por artistas plásticos. Havia um trânsito entre o periódico e os artistas, que emprestavam suas assinaturas para o produto, indicando que a associação entre ambos era proveitosa: tanto para o periódico, que conquistava prestígio cultural, quanto para o artista, que adquiria um espaço e maior visibilidade na dinâmica social.

\section{Considerações finais}

Os conceitos de inovação, modernidade e requinte perceptíveis nas páginas de Rio não estavam ali apenas para criar uma revista que agradasse seus leitores, mas também para legitimar um determinado público consumidor daqueles valores e comportamentos. $\mathrm{Ou}$ seja, davam reconhecimento aos próprios produtores da revista: a elite que a produzia e a consumia.

Ao selecionar o que deveria ser notícia ou não, valorizando determinados elementos e personagens em detrimento de outros, a revista reconstruía o presente de forma seletiva, construindo naquele presente o que deveria se lembrado no futuro e o que deveria ser esquecido. Essa construção dos fatos obedecia, portanto, a uma ordem de poder e de natureza ideológica, em que a publicação legitimava acontecimentos que interessavam ao grupo ali representado. Logo, é possível afirmar que Rio é um "lugar de memória" privilegiado, pois estão impressos em suas páginas um discurso legitimador de uma realidade.

Suas características visuais indicam uma linguagem gráfica moderna necessária para apoiar e sustentar ideias de uma elite que apresentava uma única possibilidade para vivenciar e estar no mundo. Havia assim uma integração entre o projeto editorial e o projeto gráfico 
que potencializava o discurso implícito nas páginas da revista. A organização das imagens, os closes, as poses e enquadramentos, assim como a relação entre texto e imagem diz muito dessa imbricação de projetos, pois esses aspectos elaboravam um sentido percebido e entendido por seus leitores.

Apesar do esquecimento a que foi relegada, seja por suas aproximações com o poder político ou por retratar o high life, a revista conseguiu construir uma identidade visual. Uma identidade que permaneceu, e que por isso mesmo deixou rastros e vestígios de um momento importante para o mercado editorial, pois ali estão presentes indícios do que surgiria anos depois.

Além de tudo, Rio renovava o simbolismo da capital do país, revendo e reescrevendo a cidade para o leitor, estabelecendo aí um duplo papel: o de ser um veículo moderno e de difundir um estilo moderno de ser.

\section{Referências bibliográficas}

A Revista no Brasil. São Paulo: Editora Abril, 2000.

BARBOSA, Marialva. História cultural da imprensa: Brasil 1900-2000. Rio de Janeiro: Mauad X, 2007a.

Percursos do olhar: comunicação, narrativa e memória. Niterói, EdUFF, 2007b.

O Cruzeiro: uma revista síntese de uma época da história da imprensa brasileira. In: Ciberlegenda - Revista do Programa de Pós-Graduação em Comunicação da Universidade Federal Fluminense. N. 7, 2002. Disponível em: www.uff.br/ciberlegenda/ojs/index.php/revista/ article/view/331.

BUENO, Eduardo. Passando a limpo: história da higiene pessoal no Brasil. São Paulo: Gabarito, 2007.

CAMARGO, Mário de (org.). Gráfica: arte e indústria no Brasil - 180 anos de História. São Paulo: Gráfica Bandeirantes, 2003.

CAVALCANTI, Lauro (org.). Quando o Brasil era moderno: Artes plásticas no Rio de Janeiro 1905-1960. Rio de Janeiro: Aeroplano, 2001.

CERBINO, Ana Luiza. A modernidade impressa nas páginas da revista Sombra. In: Revista Rastros - Revista do Núcleo de Estudos em Comunicação, Ano XIII, n.16, Junho de 2012. ISSN 1517-9524. pp.121-133.
Publicidade e consumo nas páginas da revista Sombra. In: Anais do XIX Intercom Sudeste - UVV/Universidade Vila Velha, 22 a 24 de maio de 2014.

Memórias impressas: fatos e personagens nos escritos de Jacques Corseuil. In: Anais do VIII Encontro Nacional de História da Mídia. Unicentro - Guarapuava/ PR, 28 a 30 de abril de 2011.

Sombra: páginas da modernidade. In: Anais do I Encontro Mundial de Comunicação Ibero-Americana. CONFIBERCOM/SOCICOM/ECA-USP. São Paulo/SP - Escola de Comunicação e Artes - ECA/USP - 31 de julho a 04 de agosto de 2011.

LUSTOSA, Isabel (org.). Imprensa, história e literatura. Rio de Janeiro: Edições Casa de Rui Barbosa, 2008.

MARTINS, Ana Luiza; LUCA, Tania Regina de. História da Imprensa no Brasil. São Paulo: Contexto, 2008.

MARTINS, Ana Luiza. Revistas em revista: imprensa e práticas culturais em tempos de República, São Paulo, 18901922. São Paulo: Edusp/Imprensa Oficial do Estado de São Paulo, 2001.

MAUAD, Ana Maria. "Flagrantes e instantâneo: fotografia de imprensa e o jeito carioca de ser carioca na belle époque". In: LOPES, Antonio Herculano (org.). Entre Europa e Africa: a invenção do carioca. Rio de Janeiro: Edições Casa de Rui Barbosa, Topbooks, 2000. p.267288.

MEGGS, Philip B. História do design gráfico. São Paulo: Cosac Naify, 2009.

MELLO, Chico Homem; RAMOS, Elaine (orgs.). Linha do tempo do design gráfico no Brasil. São Paulo: Cosac Naify, 2011.

NEVES, Margarida de Souza. Lugares de memória da medicina no Brasil. Disponível em http://www.historiaecultura. pro.br/cienciaepreconceito/frame.htm. Acesso em março/2010.

NORA, Pierre. Entre memória e história: a problemática dos lugares. In: Projeto História - Revista do Programa de Estudos Pós-graduados em História do departamento de História da PUC-SP. n. 10, dez. 1993. pp. 07-28. 
OLIVEIRA, Claudia de; VELLOSO, Mônica Pimenta; LINS, Vera. O moderno em revistas: representações do Rio de Janeiro de 1890 a 1930. Rio de Janeiro: Garamond, 2010.

RIBEIRO, Ana Paula Goulart. Imprensa e História no Rio de Janeiro dos anos 50. Rio de Janeiro: E-Papers, 2006.

Jornalismo, literatura e política: a modernização da imprensa carioca nos anos 50. In: Estudos Históricos, Midia, n. 31, 2003/1, CPDOC/FGV. Disponível em: www.latinoamericano.jor.br/aulas/JORN_INF/modernização_imprensa.pdf. Acesso em 25/08/2009.

Clientelismo, corrupções e publicidade: como sobrevivem as empresas jornalísticas no Rio de Janeiro dos anos 50. In: BARBOSA, Marialva (Org.). Estudos de jornalismo I. Campo Grande: Intercom, 2001.

SCALZO, Marília. Jornalismo de revista. São Paulo: Contexto, 2004.

SODRÉ, Nelson Werneck. História da imprensa no Brasil. Rio de Janeiro: Editora Civilização Brasileira, 1966.

SOUZA, Rogério Martins de. O cavalheiro e o canalha: Maneco Müller, Walter Winchell e o apogeu dos colunistas sociais após a Segunda Guerra Mundial. Disponível em: www.intercom.org.br/papers/nacionais/2007/resumo/ r1268-1.pdf. Acesso em 01/09/2014.

TAVARES, Frederico de Mello B.; SCHWAAB, Reges. Revista e comunicação: percursos, lógicas e circuitos. In: . A revista e seu jornalismo. Porto Alegre: Penso, 2013. pp. 27-43.

VELLOSO, Mônica Pimenta. Sensibilidades modernas: as revistas literárias e de humor no Rio da Primeira República. In: LUSTOSA, Isabel (org.). Imprensa, história e literatura. Rio de Janeiro: Edições Casa de Rui Barbosa, 2008. p. 211-230.

Percepções do moderno: as revistas do Rio de Janeiro. In: NEVES, Maria Bastos P.; MOREL, Marco; FERREIRA, Tania Maria Bessone da C.. História e Imprensa: representações culturais e práticas de poder. Rio de Janeiro: DP\&A: Faperj, 2006. pp. 312-331. 